\title{
Strategic Environmental Assessment (SEA) Process for Applied Mechanics, Mechatronics and Materials towards Sustainable Development
}

\author{
-Sustainability excellence achievements
}

\begin{abstract}
Vijayan Gurumurthy Iyer*
Professor in the Department of Civil Engineering, Koneru Lakshmaiah Education Foundation (KLEF) Deemed To Be University, Vaddeswaram, Guntur District, Andhra Pradesh, India and OLPE Counsellor and Co-ordinator, The EDI of India, Editor/Chair of AMMM2018, A-2/31, Kendriya Vihar-II, Paruthipattu, Avadi, Chennai-600 071, India.

${ }^{*}$ Corresponding author
\end{abstract}

\begin{abstract}
This research has been focussed on to the design and development of sustainable ozone layer to restore back global warming potential into original conditions. The Sustainable ozone layer is a kind of new Ozone layer development that meets the needs of the present generation's ultraviolet radiation protection requirements without compromising the ability and efficacy of the future generations to meet their own ultraviolet radiation protection requirements. Strategic environmental assessement process (SEA) can be defined as the systematic identification and evalution of the potential strategic environmental impacts of proposed projects, plans, programs, or legilative actions relative to the physical-chemical , biological , cultural, and socio-economical components of the total strategic environment. The primary purpose of the SEA process is to encourage the consideration of the sustainability in planning and design making process process and to ulitmately arrive at actions which are sustainably compatible. In this research, SEA process has been aimed to incorporate environmental and sustainability factors concerned to applied mechanics, mechatronics, and materials for project planning and decision-making process such as project formulation and appraisal of Indo-Matsushita midget electrode or Matsushita Carbon Company (MCC) plant in 1979 at Tada and cotton roller ginning plant as well as certain other projects that included policies, programs, plans and legislative actions. Sustainable development is a kind of development that meets the needs of the present without compromising the ability and efficacy of future generations to meet their own needs. Environmental Impact Assessment (EIA) process can be defined as the systematic study of the potential impacts (effects) of proposed projects, plans, programs, policies or legislative actions relative to the physical-chemical, biological, cultural, and socioeconomic components of the total environmental product life cycle. The primary purpose of the EIA process is to encourage the consideration of the environment in Organizational's planning and decision-making process (OPDM) and to arrive at actions that are environmentally compatible. OPDM process should include the integrated consideration of technical or engineering, economic, environmental, safety, and health, social and sustainability factors to achieve business excellence. Prior to the National Environmental Policy Act (NEPA) process in 1970 in the USA, technical and economic factors dominance the World's projects. The objective of the study design conceptualization of SEA process based on fifteen number of sustainable detailed project reports (DPRs) submitted by the extension learners of Diploma in
\end{abstract}

Entrepreneurship and Business Management (DEBM) course conducted by the Entrepreneurship Development Institute of India (The EDI of India) during the research year (RY) 1999 to 2018 under the author's counsellorship. The design of the study is cross sectional. SEA system is a potentially useful element of good environmental management and sustainable development; however, as currently practiced in industries, it is far from perfection. Emphasis should be given in industries on maintaining economic viability of the operation, while in turn taking care to preserve the ecological and social sustainability of the country. International EIA process required multi-disciplinary approach that has been conducted very early stage of Indo-Matsushita Midget electrode project in $\mathbf{1 9 8 2}$ at Tada for technical, economic, ecological and social sustainability [6].

Keywords-education; embed; environment; industry; engineering materials; mechanics; mechatronics; matsushita carbon company (MCC); ozone layer; sustainability

\section{INTRODUCTION}

The Sustainable ozone layer is a kind of new Ozone layer development that meets the needs of the present generation's ultraviolet radiation protection requirements without compromising the ability and efficacy of the future generations to meet their own ultraviolet radiation protection requirements. This paper on Strategic Environmental Assessment (SEA) Process for Applied Mechanics, Mechatronics and Materials Towards Sustainable Development as Engineers must design and construct projects by assessing their environmental impacts on the environment. The legislation of EIA process was established in 1970 by the enactment of the National Environmental Policy Act (NEPA) in the USA [5]. This was first time that EIA process in industries became an official tool to protect the environment. Three of the significant terms while complying with the requirements of NEPA process are "environmental inventory", "environmental impact assessment process", and "environment impact statement". EIAs of design and conceptualization were undertaken to protect environment during the year 1950 in Japan, Europe and North America [2]. The purpose of the EIA process is to encourage the consideration of the environment in organizational planning and decision-making process. Historically, the choice of 
proposed projects, policies, plans, programs, permits, procedures or legislations was primarily based on only one criterion called economic viability. Today, it is necessary to consider three criteria of economic, environmental and social viabilities. Environment coupled with quality management (EQM) is an intricate managerial approach that was the targeted research area to achieve socio-economic improvement and sustainability based on the triple bottom-line approach (economical, environmental and social) feasibility studies.

\section{MATERIALS AND METHODS}

The Sustainable ozone layer is a kind of new Ozone layer development that meets the needs of the present generation's ultraviolet radiation protection requirements without compromising the ability and efficacy of the future generations to meet their own ultraviolet radiation protection requirements. SEA process is a predictable process that is devised in to two phases. The first phase is called initial environmental and sustainability evaluation (IESE) and the second phase is environmental and sustainability impact studies (ESIS). IESE has been carried out for Japanese Matsushita carbon company's proposed project, plan, program, policy, permit, procedure, and legislative action in India to determine whether potentially adverse effects on environment and sustain efficacy with respect to physical, chemical, biological, economical, socio-economic environment and on human health and well-being are significant or whether mitigation measures can be adopted to reduce or eliminate adverse environmental and sustainability impacts. Detailed SEA procedure can be called as ESIS that was applied to identify and evaluate the environmental and sustainability consequences both beneficial and adverse impacts to ensure that the environmental and sustainability impacts were taken in to consideration in organization's planning and decision making (OPDM) process. SEA process is designed to identify and predict the potential impacts of the physical, biological, ecological, socio-economic, cultural environment and on human health and well-being are adequately protected [6]. Given below some of the methods and techniques applied for the sustainable project formulation and appraisal of fifteen DEBM extension learners of The EDI of India attached with the professional counsellor and co-ordinator for the midget electrode (Battery carbon rod) project. Expert judgment and stakeholders' sentiments

1. Check list and matrices

2. Multi criteria analysis

3. Case comparisons

4. Simulation models

5. Software and information system

6. Questionnaires

7. Group discussions

8. Delphi approach

9. Flow charts and decision trees

10. Contingency analysis

11. Overlays

12. Fuzzy logics

Environment and sustainability compliance requirements have been identified and evaluated systematically in these projects

(http://debm-ediiindia.ac.in/counsellors/student record). Fifteen DPRs of DEBM Learners were formulated and appraised.

\section{A. Step-wise Structure of SEA Process}

SEA Process has been itemized by the following nine steps.

1. Preliminary activities and decision of Terms of References (TOR)

2. Scoping

3. Study of base line data

4. Strategic environmental assessment and evaluation,

5. Evaluation of alternative measures

6. Assessment of alternative measures

7. Preparation of final documents

8. Decision-making

9. Monitoring, measurement and control opportunities for resource transformation and project implementation and its strategic environmental assessment process.

\section{B. Conceptual Framework for Screening and Scoping of SEA}

\section{Process}

Screening and scoping processes are the items which are employed in the SEA processes (Figure I). Three most significant items are," Strategic environmental assessment inventory, environmental impact assessment, strategic environmental impact assessment statement. Constructional planning and decision-making process should include the integrated consideration of technical, economic, environmental, social, safety, health and sustainability factors (Figure II).

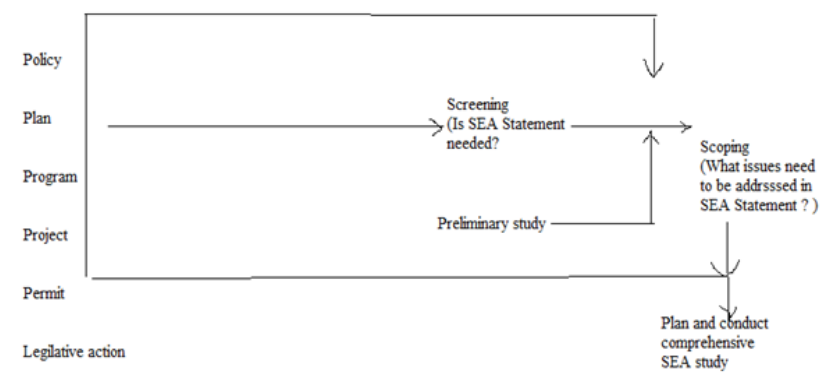

FIGURE I. CONCEPTUAL FRAMEWORK FOR SCREENING AND SCOPING PROCESSES OF SEA PROCESS

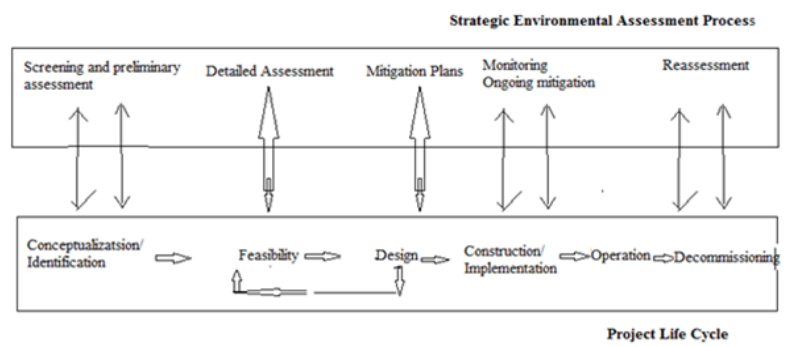

FIGURE II. TRATEGIC ENVIRONMENTAL ASSESSMENT (SEA) PROCESS AT DIFFERENT HASES OF PROJECT LIFE CYCLE ASSESSMENT

\section{Strategic Environmental Assessment Management Plan (SEMP)}

A strategic environmental assessment management plan is a detailed plan and schedule for measures to minimize and mitigate any potential environmental and sustain efficacy 
impacts. SEMP should consist of a set of measurement, monitoring, control (mitigative) and institutional measures to be taken during the implementation and operation of the proposed projects to eliminate adverse environmental and sustainability impacts, offset them or reduce them to acceptable levels. Strategic environmental assessment process aims to incorporate environmental and sustainability considerations in to strategic planning and decision-making processes of the project formulation and appraisal. International EIAs are important considerations in project planning and decision-making process. It has been imperative to consider international EIAs in concrete project to mitigate $\mathrm{CO}_{2}$-induced climate warming problem and stratospheric ozone depletion problem. International EIA process is a potentially good environmental management [2].

Environmental Health Impact Assessment (EHIA) process has been conducted for projects to consider the safety and health impacts to mitigate psychological health loadings on workers and nearby residents. Social Impact Assessment (SIA) process can be defined as the systematic identification and evaluation of the potential social impacts (effects) of proposed projects, plans, programs, or legislative action such that social consideration is encouraged in OPDM process and to arrive at actions that are socially compatible. International EIA process required multi-disciplinary approach that has been conducted very early stage of Japanese Matsushita carbon rod project in 1982 for strategic environmental assessment. The paper highlights SEA process conducted for certain projects that based on operation and process approach and associated studies for sustainable development. Engineering product environmental lifecycle analysis (LCA) has been conducted for identifying and measuring the impact of certain industrial products on the environment by means of mass and energy balance methods. LCA considers the activities related to raw materials, transformation, ancillary materials, equipment, method, market, man power, production, use, disposal and ancillary equipment. As far as safety is concerned personal protective equipment and materials (PPEMs) that include garments, clothing, gloves, safety shoes, hard hats, safety glasses, shields, respirators, full aprons, safety belts, and other safety items which must be used by an individual. Such equipment is important for personal protection and for safety. It is the manager's and supervisor's responsibility to ensure that they are used. The enactment of worker's compensation law and occupational disease law shall increase materially the cost of insurance to industry. The increased cost and the certainty with which it is applied will put a premium on accident-prevention work. This cost can be materially reduced by the installation of safety devices. Research experience has shown that approximately $80 \%$ of all the industrial accidents are preventable. EIA and EHIA processes have been conducted for research projects to consider the safety and health impacts to mitigate psychological health loadings on workers and nearby residents.

\section{RESUlTS AND DiscussiOnS}

Unsustainable developments with reference to applied mechanics, mechatronics, and materials that have unsustained the environmental growth. Sustainability of design and development, quality of life, safety on earth and continuous process improvement of our environment is of utmost important. Sustainable development means a kind of constructional development that should be occurred without damages to the environment. Hence, hectic constructional developmental activities during the last two centuries have caused considerable environmental and social impacts. These impacts have been measured, monitored and mitigated by international environmental impact assessment process (Figure III).

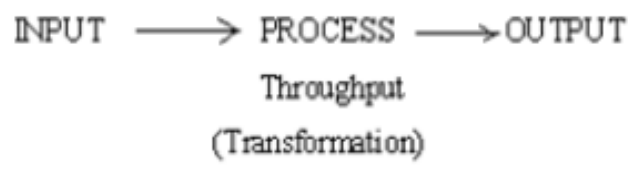

FIGURE III. CONSTRUCTION MANAGEMENT BY PROCESS
APPROACH

International EIAs are important in an international project planning and decision-making process that mitigates potential environmental impacts in more than one country (Ref. IndoMatsushita Carbon Company limited). The use of sustainable technology and management in environmental and sustainability matters in two areas that is sustainable development with global problems and prevention technologies that are designed to reduce the environment effects of products and processes (Figure IV).

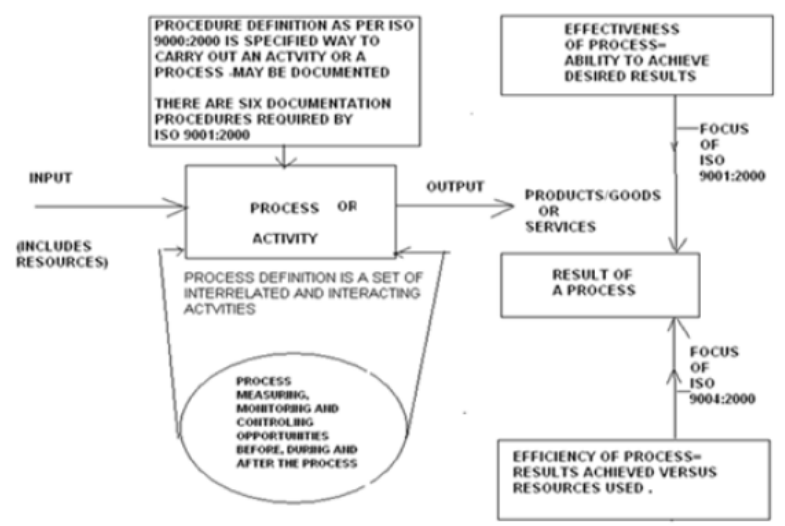

FIGURE IV. SCHEMATIC DIAGRAM OF A CONSTRUCTION PROCESS

The integration of environmental protection and economic development is the most important strategic environmental assessment tool in achieving sustainable development (Figure V). Project planning and decision-making should include the integrative consideration of engineering or technical, economic, environmental, ethical and social factors. A midget electrode project has been considered a special case study for the strategic environmental assessment process (Figures $\mathrm{V}$ and $\mathrm{VI}$ ). International EIA process has been designed for the sustainable midget electrode project design and construction to identify and predict the potential effects of the physical, biological, ecological, socio-economic, cultural environment and on human health and well-being are adequately protected. Environmental Impact Statements (EIS) have been prepared for the project which considering environmental and socio-economic factors with respect to development and other 
proposed actions. Therefore, the EIA system is a potentially useful component of good environmental management [2].

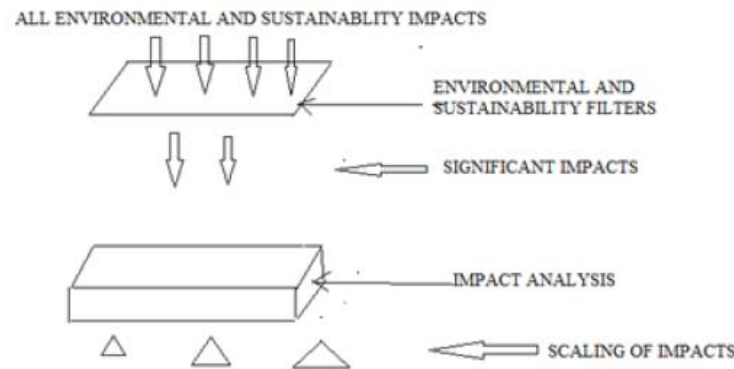

FIGURE V. PROCEDURE FOR FINDING OUT THE SIGNIFICANCE OF ENVIRONMENTAL AND SUSTAINABILITY EFFECTS

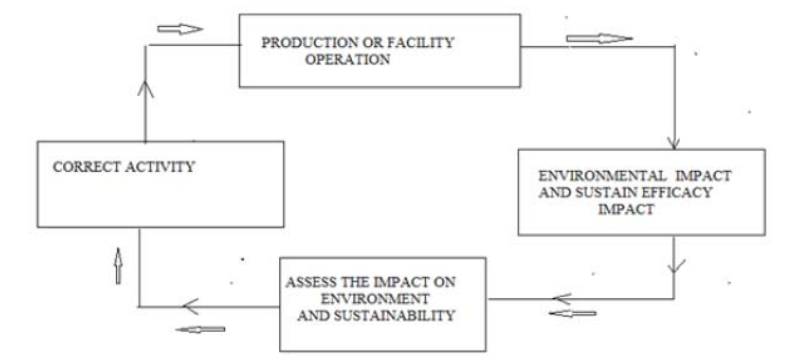

FIGURE VI. ENVIRONMENTAL AND SUSTAINABILITY ENTITLED “AFTER-THE-FACE” EVALUATION

The Sustainable ozone layer is a kind of new Ozone layer development that meets the needs of the present generation's ultraviolet radiation protection requirements without compromising the ability and efficacy of the future generations to meet their own ultraviolet radiation protection requirements. Low carbon and energy efficient technology of construction industries can make contributions to mitigating impacts of economic growth on global warming (Figure VII) .The resultant output of green products and services which are environmental advantages with superior performance and cheaper prices. The dual goals of green design are the waste prevention and better material management as depicted in Figure VII. Design and construction of green buildings that has considerably reduced the environmental impacts associated with manufacturing, use and disposal. Prior to the enactment of National Environmental Policy Act on Environment in1970 in the USA, only technical or engineering and economic factors dominant in planning and decision-making process in most of the world projects, plans, programs, permits, policies and legislative actions. As per the research results that project planning and decision-making process must include the integrated consideration of engineering or technical, economic, environmental, safety, ethical, social and sustainability factors. This important consideration can be referred to as "Concept of the Four Es and $1 \mathrm{~S}$ " in organizational planning and decisionmaking process. There are ecological and biogeochemical principles and tools such as energy flows and material cycling, element ratios, mass and energy balance, element cycling, product environmental Lifecyle assessment (LCA) (Figure VIII) are available to solve major environmental problems that we face in our world today such as global warming, acid rain, environmental pollution and increasing greenhouse gases.
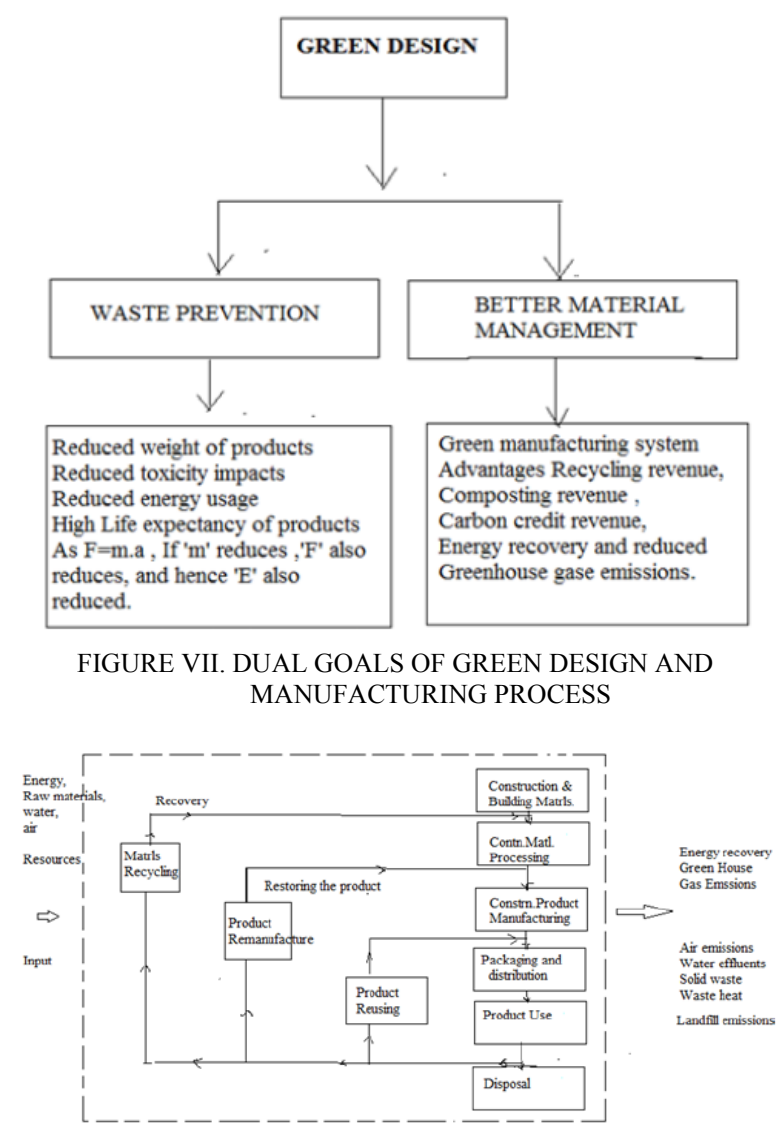

FIGURE VIII. CONSTRUCTION PRODUCT ENVIRONMENTAL LIFECYCLE ANALYSIS (LCA)

Engineering product environmental lifecycle analysis (LCA) is conducted for identifying and measuring the impact of industrial products on the environment and sustain efficacy by means of mass and energy balance methods (Figure VIII). LCA consider the activities related to extraction of raw materials, ancillary materials, equipment production, use, disposal and ancillary equipment [2].

\section{A. Environmental Health Impact Assessment (EHIA) Process for Nuclear Power Plant Project towards Sustainable Constructional Development}

An environmental health impact assessment (EHIA) process is proposed in this research for nuclear power plant project during the construction phase to address psychological health impacts on workers and nearby residents. Environmental health impact assessment can be defined as the systematic identification and evaluation of the potential environmental health impacts or effects of proposed nuclear power projects, plans, programs, policies or legislative actions relative to the physical-chemical, biological, cultural and socioeconomic components of the total environment. At present there are more than four hundred thirty-seven nuclear power plants situated in the World. It may be worth mentioned that none of the nuclear power projects, plans, programs, policies, or legislative actions in the World have got sustainable practice in conduction of EHIA. Nuclear power plants generate electricity using heat generated in pressurized water reactors where nuclear reaction 
takes place. During the construction phase of nuclear power plants which use Uranium-235, Thorium-232 and Plutonium-239 as fuels in nuclear reactors causing nuclear fission. That time copious amount of radiation dose due to radioactive pollution escaping out in the order of about 120 billion Becquerel (120 GBq) to 240 billion Becquerel (240 GBq) that is 50 grams to 100 grams, radiation activities viz., Alpha $(\alpha)$, Beta $(\beta)$ and Gamma $(\gamma)$ as against the safe limits of $0.1 \mathrm{~Bq}$ $/ 1$ or $\mathrm{Bq} / \mathrm{kg}(\mathrm{ppm})$ in land, air and water when operation, repair and maintenance of replacing old nuclear fuels with new fuels taken place. High exposures to radioactive pollution damage mental health and psychological burden on workers and nearby residents. As per a psychological health impact survey conducted by the author in a nuclear power plant at Quinson, China, severe psychological disorders including radioactive poisoning, depression and post-traumatic stress have been investigated to an extent among $49 \%$ of the nearby residents in and around $82 \%$ of the nuclear power plants in the World. Psychological health impact loadings due to radioactive environment on workers and nearby residents have been studied in this research during the test run phase using computer simulation models. Psychological health impact assessment (PHIA) on workers and nearby residents have been addressed to mitigate psychological health impact loadings on workers and nearby residents.

\section{B. Environmental Health Impact Assessment (EHIA) Process for Sustainable Development}

In this research, EHIA process has been investigated on cotton double roller (DR) ginning industries using chrome composite leather clad (CCLC) washers and design and development of an eco-friendly alternative. The objective is to assess the environmental health impacts of Indian cotton ginning industries. Most of the cotton ginning operations are performed by using DR ginning machines which serve a key role in the Indian cotton ginning industries. The rollers used are made of CCLC covering fixed to a shaft. The CCLC contains about 18,000 to $36,000 \mathrm{mg} / \mathrm{kg}$ (ppm) of chromium particles. When the seed-cotton is processed in DR ginning machine, the lint cotton is contaminated with hexavalent chromium dust of about 140 to $1990 \mathrm{mg} / \mathrm{kg}$ (ppm) which is carcinogenic substance against the safe limits of $0.1 \mathrm{ppm}$. During the cotton ginning process due to persistent rubbing of CCLC over stationary knife the chromium particles are adsorbed into lint cotton such that the spun yarns and woven fabrics get contaminated about 100 to $200 \mathrm{ppm}$ which according to World Health Organization (WHO) eco-standards should not be more than $0.1 \mathrm{ppm}$. The CCLC rollers used in cotton roller ginning machines get powdered during the ginning process. As chromium is a specific dust, gin and mill workers and residents are directly exposed to this carcinogenic substance and are vulnerable to environmental health hazards. To offset this problem, pollution-free eco-friendly washers/rollers both for laboratory and commercial studies have been fabricated and experimented. Environmental health inventory (EHI) serves as the basis for evaluating the potential environmental health impacts both beneficial and adverse of a proposed action. Environmental health impact statement (EHIS) describes the affected environmental health or environmental health setting without the project. Design and development of the EHI is an initial step in the EHIA process. It is concluded that EHIA process should be conducted for certain projects, plans, programs, legislative actions, policies in the project planning and decision-making process.

\section{International EIA Process}

International EIA process is a potentially good environmental management system (EMS). International organization for Standardization (ISO)'s 14000 and 9000 standards focus on Environmental Management System (EMS) and Quality Management System (QMS) of all sorts of organizations apart from more than 19500 published standards. Environmental Management System (EMS) and Quality Management System (QMS) have been separately featured in ISO. Environmental Management System (EMS) standards apply to the management system concepts of an organization's environmental issues and opportunities [1]. It defines the features of an EMS that need to be in place to ensure that the organization identifies and focuses on improving areas where they have significant environmental impacts. This system can be integrated with ISO 9000 Quality Management System (QMS) standards to achieve excellence in quality as well as environmental obligations. The overall aim of the EMS is to provide protection to the environment and to prevent pollution to manufacture eco-friendly products and services. EMS focuses on key drives of performance excellence in products and processes as well as organizations that are focused on delivering values to the customers, internal operational processes, and to staff's learning. Hence, this system approach to the environmental management shall achieve excellence in the overall performance of the organization. In the present study about two third of construction waste was recoverable due to the conduction intensive on-site training programs on recycling and composting processes as against the conventional construction management practices which could able to recover the waste of only 10 to $15 \%$.

Wastes are produced by industrial sector. The study has been attempted to identify and evaluate special waste minimization hierarchy of waste management for properly managing industrial waste including minimizing generation and treatment that have been generated and disposing of waste residuals. A case study has been included on generation of construction wastes and potential waste management strategies for a group or generic, source specific and specific industrial processes. All processes generate wastes in the form of liquids, solids or gases. IMCL wastes may be characterized and assessed as hazardous. The waste minimization hierarchy of waste management is duly ranked from most desirable to least desirable (Figure IX). 1. Eliminating waste generation -Most desirable, 2. Reducing waste generation- Most desirable, 3. Reuse, recover or recycle waste materials- Most desirable, 4. Treating waste to diminish quantity and to detoxify the hazardous and non-hazardous solid wastes --Least desirable, 5. Disposing of waste residuals- Least desirable. Waste minimization include only elimination, recovery, reduce, reuse and recycle hierarchies. Waste minimization does not include treatment of wastes as well disposal that is point number 4 and point number 5 because, these are traditional waste control strategies involves treatment and disposal which are called end-of-the pipe solutions and are costly affairs as well as involve control of high discharge standards. Modern waste 
control strategies involve point number 1 , point number 2 and point number 3 which are not requiring end-of- the pipe solution for the waste management problems. Solid and hazardous waste generation is the sum of material recovery and discards. Report on waste audit conducted for a construction industry is presented for recovering two-third of municipal solid wastes (MSW) by recycling and composting processes (Figures $\mathrm{X}$ and Figure XI).

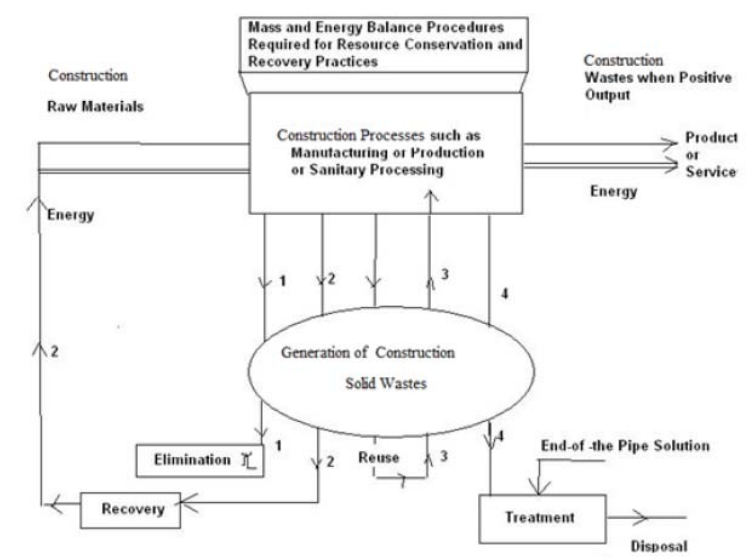

FIGURE IX. SCHEMATIC REPRESENTATION OF INDUSTRIAL PROCESS OR ACTIVITY SHOWING SUSTAINABLE WASTE MANAGEMENT

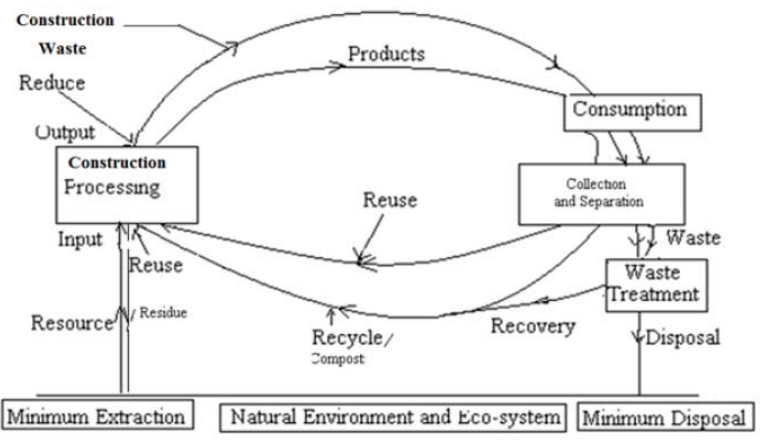

FIGURE X. CLOSED LOOP-SHAPED GREEN ECONOMY FOR SUSTAINABLE WASTE MANAGEMENT

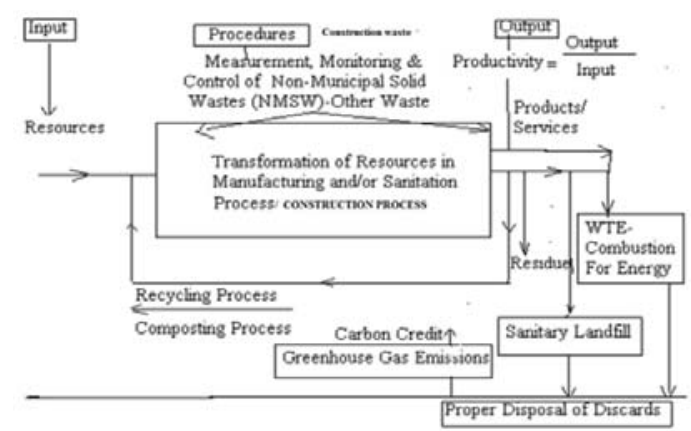

FIGURE XI. SUSTAINABLE WASTE MANAGEMENT SYETEM

To achieve the sustainable economic improvement, natural resources to be utilized at optimum level to maximize efficiency and maximize effectiveness as per the result analysis of optimum competitive and social markets. The efficiency of a kind of sustainable economic system is referred in "A.K" sustainable economic model that is the product of engineering or technical factor level (A) and the capital (K). The sustainable economic improvement is explained by three factors which are given below: -

The natural increase in the accumulation of labor potential,

Capital accumulation or money with which a business is started and run;

Sustainable technological momentum can be referred as total factor productivity (TFP) or efficiency in construction process.

Such momentum keeps the capital development dynamic which emerges from the sustainable enterprise creation process, green products or services, new methods of production and processes, new construction management and transportation, new markets and new forms of constructional organization.

Standard Production Function (SPF) is expressed based on operation approach as

$$
\mathrm{Y}=\mathrm{f}(\mathrm{C}, \mathrm{L})
$$

Where $\mathrm{Y}=$ Output, $\mathrm{C}=$ Capital, and $\mathrm{L}=$ Labour

As knowledge is a crucial factor for the economic growth,

Standard Production Function (SPF) is modified based on process approach as

$$
Y=A . f\left(X_{1}, X_{2}, X_{3}, X_{4}, X_{5}, X_{6}\right)
$$

'A' represents Knowledge on sustainable constructional engineering or technical factor,

$$
\mathrm{Y}=\text { Output, }
$$

Input elements are namely, man power, machinery, materials, method, money and market denoted as $X_{1}, X_{2}, X_{3}, X_{4}$, $\mathrm{X}_{5}, \mathrm{X}_{6}$

$\mathrm{f}=$ Standard production function.

As per the given standard production function, knowledge is a decisive production variation, sustainable innovation level is required in engineering or technical system. The solution is the development of reformed SEA process implemented industries.

\section{Conduct of Social Impact Assessment (SIA) Study}

Social Impact Assessment (EIA) process is a systematic identification and evaluation of potential social effects of proposed projects, plans, programs, plans or legislative actions relative to the society. The purpose of the SIA process is to bring about a sustainable and equitable biophysical and human environment. SIA process includes the monitoring, measurement and control opportunities including analysis and management of the intended and unintended social consequences whether both positive and negative impacts of planned interventions and any changes takes place in social transformation process invoked by those interventions. The SIA process should include the analysis of the use of land, culture, industrial process, economic development, and their impact on service sectors such as water use, energy use, sanitation and traffic. SIA process is done to ensure that there is 
no mismatch between the constructional development and socio-cultural and economic development of the project areas.

\section{E. Total Quality Management (TQM) and Environmental Quality Managment (EQM)}

TQM is a comprehensive and structured approach to construction sector that seeks to improve the quality of services through ongoing refinements in response to continuous feedback. TQM leads to sustainable constructional development. International Organizational for Standardization's ISO 9000 series define TQM as a management approach centered on quality, based on the participation of all its members and aiming at long term success through customer satisfaction and benefits to all members of the organization and society. Hence, TQM is based on quality management from the customer's point of view. TQM processes are divided into four sequential categories: plan, do, check, and act (Figure XII). This is also called the PDCA cycle or Deming's cycle for continuous process improvement. In the planning phase, constructionists define the problem to be addressed, collect relevant data, and ascertain the problem's root cause; in the doing phase, constructionists develop and implement a solution, and decide upon a measurement to gauge its effectiveness and efficiency; in the checking phase, constructionists confirm the result through before-and-after data comparison; in the acting phase, constructionists document their results, inform others about process changes, and make recommendations for the problem to be addresses in the next PDCA cycle. ISO 9000 series focus on quality management for all sorts of organizations. It defines the features of quality management system (QMS) that need to be in place to ensure that identify and focus on improving the areas where they have significant constructional deficiencies [1].

The ISO 14000 Environmental Management System (EMS) standards apply to the management system to manage an organization's environmental issues and opportunities [1]. It defines the features of an EMS that need to be in place to ensure that the organization identifies and focuses on improving areas where they have significant environmental impacts. This system has been integrated with ISO 9000 Quality Management System (QMS) standards to achieve excellence in quality as well as environmental obligations in midget electrode project. The overall aim of the EMS is to provide protection to the environment and to prevent pollution to manufacture eco-friendly products and services. The ISO 14000 series of standards assist the organizations to excel environmental and economic gains for continuously improving organizational performances. They are used for prevention of pollution, reduction in wastes, enhancement of internal management system efficiency, optimum utilization of resources and compliances for legal and regulatory requirements. EMS can be basically divided into five events which form the sequence of a cycle (Figure XIII). These five events are (1) Environmental Policy, (2) Environmental Planning, (3) Environmental implementation and operations, (4) Checking and corrective actions, and (5) Management Review. The ISO 14000 series of standards have also been designed to cover the areas of environmental issues and opportunities for the organizations to compete the global customer centric markets so that the products and services can be manufactured at par with the international requirements [1].

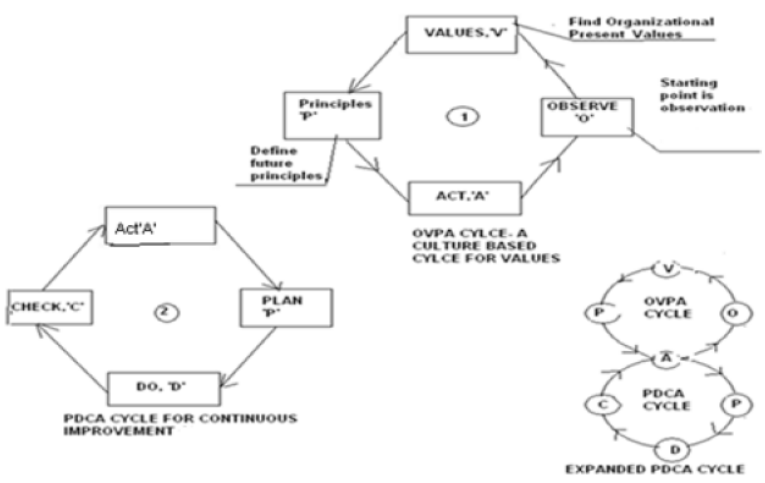

FIGURE XII. CONCEPTUALIZATION OF CULTURE BASED ENVIRONMENTAL AND QUALITY MANAGEMENT ENTITLED" OVPA" CYCLE BY INCORPORATING THE EXPANDED PDCA CYCLE

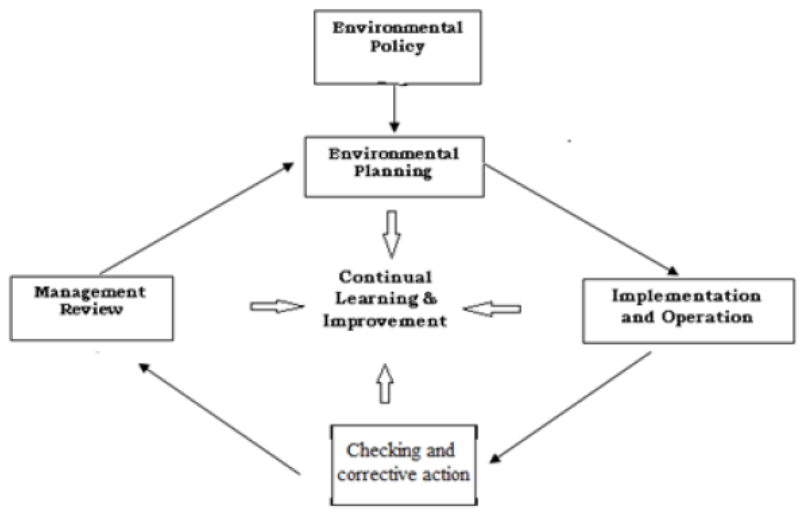

FIGURE XIII. ENVIRONMENTAL MANAGEMENT SYSTEM

EMS focuses on key drives of performance excellence in products and processes as well as organizations that are focused on delivering values to the customers, internal operational processes, and to staff's learning. It may be mentioned that Environment and Quality Management (EQM) is a managerial approach centered on environment and quality through beneficiary satisfaction in construction industries that lead to economic improvement and sustainability. Hence, this system approach to the environmental management shall achieve excellence in the overall performances of the organization.

\section{F. Conclusions and Recommendations}

This research has been focussed on to the design and development of sustainable ozone layer to restore back global warming potential into original conditions. The Sustainable ozone layer is a kind of new Ozone layer development that meets the needs of the present generation's ultraviolet radiation protection requirements without compromising the ability and efficacy of the future generations to meet their own ultraviolet radiation protection requirements.

This research paper on Strategic Environmental Assessment (SEA) Process for Applied mechanics, Mechatronics and Materials Towards Sustainable Development is research orientation based on interdisciplinary and integrative approach as engineers must design and construct projects by assessing 
their environmental and social impacts on the environment. EIA and EHIA processes have been conducted for certain projects to consider the safety and health impacts to mitigate psychological health loadings on workers and nearby residents. SEA process system is a potentially useful element of good environmental management and sustainable development; however, as currently practiced in industries, it is far from perfection. Emphasis should be given in industries on maintaining economic viability of the operation, while in turn taking care to preserve the ecological and social sustainability of the country. International EIA process required multi-disciplinary approach that has been conducted very early stage of Indo-Matsushita carbon rod (MCC) project in 1982 at Tada for economic, environmental and social viabilities[10].

\section{ACKNOWLEDGEMENT}

This research was financially self-supported. The author is thankful to Sri. Koneru Satyanarayana, President, Koneru Lakshmaih Education Foundation (KLEF) Deemed to be University, Vaddeswaram, Guntur district, Andhra Pradesh, India for encouragement to publish this research paper. The author is thankful to the organizers of 2018 International Conference on Applied Mechanics, Mechatronics, and Materials (AMMM2018) for Editor /Chair service requisition and publication of this research paper in Atlantis Press. The author extends his gratitude to the DEBM Cell of Entrepreneurship Development Institute of India (The EDI of India) .

\section{REFERENCES}

[1] Giri., C.C. et.al.(2003), Importance of the ISO 14000 in Textile Industry and its Implementation Framework, Journal of Textile Association, July-Aug.2003, pp.5763 (2003)

[2] Glynn Hendry J and Gary W.Heinke, (2002) "Environmental Science and Engineering“", Prentice -Hall of India Private Limited Second Edition, 2002.

[3] Ralph A.Wurb, (2010) "Water Resources Engineering”, Prentice -Hall of India Private Limited, 2010 edition.

[4] Metcalf\& Eddy, Inc.(2012) “Wastewater Engineering, Treatment and Reuse, McGraw Hill Education (I) Private Ltd. 2012 Edition.

[5] Larry W. Canter, "Environmental Impact Assessment", McGraw-Hill International Editions 1996, Second Edition (ISBN 0-07-114103-0), PP.2.

[6] Iyer Vijayan Gurumurthy(2015), "Environmental and Quality Management for the Higher Education Institutions to Achieve Research and Academic Excellence", Journal of Modern Education Review (JMER), ISSN 2155-7993,USA, November 2015, Volume 6, Number 2 , PP. 135-146 (12 pages) @Academic Star Publishing Company 2015, http://www.academicstar.us.

[7] Iyer, Vijayan Gurumurthy (2018). "Strategic Environmental Assessment (SEA) Process Towards Sustainable Construction Management Development for the Electrical, Automation and Mechanical Engineering Construction Industries to Achieve Business Excellence". In the Proceedings and Abstract Book of the 20183 rd International Conference on Electrical, Automation and Mechanical Engineering (EAME2018) CD-ROM , http://www.eame2018.org/June 24-25, 2018 Xi' an, China and as General Chair of EAME 2018, Publication by Atlantis Press (Open Access Scientific Publishing) book entitled "Advances in Engineering Research (AER) (ISSN:2352-5401) Published by Dr.Vijayan Gurumurthy Iyer, Editor of AER.

[8] Iyer, Vijayan Gurumurthy (2018). "Study of Reciprocal Accountability and Total Quality Management in Education Sector and Its Ideal Implementation Towards Sustainable Development". In the Proceedings and Abstract Book of the International Conference on Computational Modelling, Simulation and Mathematical Statistics (AMMSA2018) CD-ROM held during May 27-28, 2018 at Sanya, China and as
Edtior/General Chair of AMMSA2018 http://www.ammsa2018.org/com.html May 27-28 Publication by Atlantis Press (Open Access Scientific Publishing) of series of Book book entitled "Advances in Intelligent Systems Research (AISR), pp.402-411, ISBN: 978-94-6252-529-0, ISSN 1951-6851 volume: 443; Published by Dr.Vijayan Gurumurthy Iyer, Editor of AISR. Publication date June 2018. https://www.atlantis-press.com/proceedings/ammsa-18/publishing

[9] Iyer, Vijayan Gurumurthy (2018). "Total Quality Management (TQM) or Continuous Improvement System (CIS) in Education Sector and Its Implementation Framework Towards Sustainable National Development". In the Proceedings of the ASSEHR 2018 International Conference on Education Reforms and Management Science (ERMS2018) CD-ROM held at Wuhan, China during April 22-23 Beijing, China as General Chair of ERMS2018 , http://www.erms2018.org/ Published by Atlantis Press (Open Access Scientific Publishing) in the Book entitled "Advances in Social Science, Education and Humanities Research (ASSEHR)", (ISBN: 978-94-6252-524-5, ISSN 2352-5398) Published by Dr. Vijayan Gurumurthy Iyer, Chair/Editor of ASSEHR, pp.133-147.

[10] Iyer, Vijayan Gurumurthy (2018). "Total Quality Management (TQM) in Education Sector and Its Implementation Framework Towards Sustainable International Development". In the Proceedings of the 2018 International Conference on Computer Science, Electronics and Communication Engineering (CSECE2018) CD-ROM held at Wuhan, China during February 7-8, 2018 as General Chair of CSECE2018, http://www.csece2018.org, Book entitled "Advances in Computer Science Research (ACSR), Volume 80, ISSN: 2352-538X, ISBN 978-94-6252-487-3 Published by Editor Dr.Vijayan Gurumurthy Iyer, Editor of ACSR. doi:10.2991/csece-18.2018.119. Atlantis Press (Open Access Scientific Publishing), pp. 546-555.

[11] Iyer, Vijayan Gurumurthy (2017). "Total Quality Management (TQM) in Education Sector and Its Implementation Framework Towards Sustainable National Development". In the Technical Volume Proceedings of the 32 nd Indian Engineering Congress, Theme entitled "Innovation in Engineering: Competitive Strategy Perspective" (ISBN: 978-93-86724-29-8) held during 21 st-23 rd December 2017 at Chennai Organized by The Institution of Engineers (India) Published by Excel India Publishers, New Delhi, Proceedings page number 412-421. 